Territorios 31 / Bogotá, 2014, pp. 85-108

ISSN: 0123-8418

ISSNe: 2215-7484

Acción colectiva en las ciudades latinoamericanas

\title{
Acciones colectivas y políticas públicas territoriales: el caso de las víctimas en Medellín
}

Collective Actions and Territorial Public Policies: the Case of Victims in Medellin

Ações coletivas e politicas públicas territoriais:

o caso das vitimas em Medellín

James Gilberto Granada Vahos*

Jonathan Alejandro Murcia ${ }^{* *}$

Recibido: 20 de mayo de 2014

Aprobado: 8 de agosto de 2014

Doi: dx.doi.org/10.12804/territ31.2014.04

Para citar este artículo:

Granada Vahos, J. G., \& Murcia, J. A. (2014). Acciones colectivas y políticas públicas territoriales: el caso de las víctimas en Medellín. Territorios, (31), 85-108. Doi: dx.doi.org/10.12804/territ31.2014.04

\begin{abstract}
* Trabajador Social; Magister en Ciencias Politicas. Profesor e investigador del Instituto de Estudios Politicos, Universidad de Antioquia. Correo electrónico: james.granada@udea.edu.co ** Politólogo; candidato a Magister en Derecho. Investigador asociado al Instituto de Estudios Politicos de la Universidad de Antioquia; docente del pregrado en Ciencia Política de la Universidad de Antioquia. Correo electrónico: jonathan. murcia@udea.edu.co
\end{abstract}


Palabras clave

Acciones colectivas, politicas públicas territoriales, victimas, territorios, enfoque territorial.

Keywords

Collective actions, territorial public policies, victims, territories, territorial approach.

Palavras-chave

Ações coletivas, politicas públicas territoriais, vitimas, territórios, enfoque territorial.

\section{territarias 31}

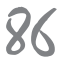

\section{RESUMEN}

En este artículo, que presenta resultados del proyecto "Políticas públicas territoriales en Medellín, actores, recursos y oportunidades. Las políticas públicas de desplazamiento forzado, y de las diversidades sexuales y de género", se propone realizar una lectura de las acciones colectivas de la población víctima en Medellín en relación con las políticas públicas territoriales de atención a víctimas, de esta manera se continúa con una agenda investigativa sobre esos dos temas y sus relaciones: las acciones colectivas de las víctimas del conflicto armado y las políticas públicas territoriales en Medellín y Antioquia. En el texto, se desarrolla un contexto general de la política pública de víctimas y algunos de sus antecedentes en la política de desplazamiento forzado; así mismo, se hace una aproximación a las acciones colectivas de las víctimas en y de la política pública territorial, se aborda brevemente lo que pasa de las políticas nacionales a los territorios, la relación con estos expresada en la descentralización y en los enfoques territoriales; y se finaliza con algunas consideraciones sobre el vínculo, en Medellín, de las acciones colectivas y las políticas públicas de las víctimas del conflicto armado.

\section{ABSTRACT}

This paper presents results of the project "Territorial public policy in Medellín, actors, resources and opportunities. The public policies of forced displacement, and sexual and gender diversity". It proposes a reading of collective actions of the victim population in Medellín, regarding with territorial public policy in attention to victims. So it continues with a research agenda on these two issues and their relationships: the collective actions of the victims and territorial public policies in Medellín and Antioquia. In this text is developed a general context of the public policy of attention to the victims and a little history of the forced displacement policy. Also makes an approach to the collective actions of the victims in the territorial public policy, briefly discusses what happens from national policies to the territories, the relation expressed in the decentralization and territorial approaches. This paper ends with some considerations on the relationship at Medellín between collective action and public policy for the victims of the armed conflict.

\section{RESUMO}

Neste artigo, que apresenta resultados do projeto "Políticas públicas territoriais em Medellín, atores, recursos e oportunidades. As políticas públicas de deslocamento forçado, e das diversidades sexuais e de gênero", se propõe realizar uma leitura das ações coletivas da população vítima em Medellín em relação com as políticas públicas territoriais de atenção a vítimas, de esta forma continua-se com uma agenda investigativa sobre esses dois temas e suas relações: as ações coletivas das vítimas do conflito armado e as políticas públicas territoriais em Medellín e Antioquia. No texto, desenvolvese um contexto geral da política pública de vítimas e alguns de seus antecedentes na política de deslocamento forçado; da mesma forma, se faz uma aproximação às ações coletivas das vítimas em e da política pública territorial, aborda-se brevemente o que acontece das políticas nacional aos territórios, a relação com eles expressada na descentralização e nos enfoques territoriais; e finaliza-se com algumas considerações sobre o vínculo, em Medellín, das ações coletivas e as políticas públicas das vítimas do conflito armado. 


\section{Introducción}

Este artículo se ocupa del tema de las acciones colectivas de las víctimas del conflicto armado $^{1}$ en Medellín, de las políticas públicas territoriales y de la relación entre estas dos categorías; el texto se inscribe en el número temático de la revista sobre 'acción colectiva en las ciudades latinoamericanas', y en la pretensión de discutir sobre la acción colectiva urbana contemporánea, en el caso de Medellín (Colombia). Así mismo, presenta algunas discusiones sobre la descentralización del Estado y sus instituciones en relación con el tema de las políticas públicas; a la vez, pretende cuestionar la idea que ve las políticas públicas territoriales solo como la expresión de políticas más generales en un territorio concreto, específico y mejor delimitado. Se pretende también avanzar en los elementos políticos propios de las políticas públicas expresados en los territorios. Se propone entonces realizar una lectura de las acciones colectivas de la población víctima en Medellín en relación con las políticas públicas territoriales de atención.

Además, el artículo desarrolla una agenda de investigación que se vincula con dos antecedentes importantes: i) La agenda del Grupo de Investigación Estudios Políticos (GIEP) y de la Línea de Investigación Migraciones, Fronteras y Reconfiguraciones Políticas (LMFRP) del IEP de la Universidad de Antioquia. ii) Las propuestas y avances teórico-metodológicos de la LMFRP que se han expresado en observatorios 'sobre el desplazamiento forzado' y de 'fenómenos sociopolíticos'.

Para este artículo, se describe someramente la metodología utilizada en el proyecto al que corresponde. ${ }^{2}$ Se puede afirmar, retomando a Elisa Chuliá y Marco V. Agulló (2012), que en ciencia política esa vertiente en la investigación que pretende describir y explicar los hechos políticos se enmarca en lo que se conoce como 'ciencia política empírica’ (p. 22), así fue el caso de este proyecto de investigación, en donde se pretendió describir y explicar. Sin embargo, a pesar de que es un trabajo especialmente empírico, tuvo una especial labor documental en la que se rastreó y se sistematizó información disponible en la web, en las bases bibliográficas de la Universidad de Antioquia y de la LMFRP.

Para precisar cómo se va de lo conceptual a lo metodológico, afirman Chuliá y Agulló, que "la política se halla por definición asociada a la diversidad de opiniones y preferencias sociales sobre cuestiones de interés común, al poder y a las relaciones que se establecen al ejercerlo. Las investigaciones en ciencia política empírica analizan esta naturaleza conflictiva de la política con el fin prioritario de entenderla mejor, no de superarla" (p. 23).

Así, en este proyecto no se pretendió intervenir directamente en la situación empírica estudiada y, por lo mismo, la metodología se orientó a la recolección de información, la sistematización, descripción y análisis de esta. No obstante, existe un compromiso de la Universidad,
${ }^{1}$ En adelante se utilizará especialmente el término 'victimas', solo, pero con este se refiere en todos los casos a victimas del conflicto armado en Colombia.

${ }^{2}$ Este artículo expone resultados del proyecto de investigación "Politicaspúblicas territoriales en Medellín, actores, recursos y oportunidades. Las politicas públicas de desplazamiento forzado, $y$ de las diversidadessexuales $y$ de género". Financiado por el Instituto de Estudios Políticos (IEP) y el Comité para el Desarrollo de la Investigación (CODI) de la Universidad de Antioquia (Colombia), continuando con una agenda investigativa sobre las acciones colectivas de las victimasy las políticas públicasterritoriales en Medellin y Antioquia en la Linea de Investigación Migraciones, Fronteras y Reconfiguraciones Politicas del Grupo de Estudios Políticos.

territarias 31

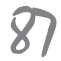


${ }^{3}$ Las categorias del proyecto se centraron en: 'politica pública' y 'enfoques', como categorias generales y no operacionalizables. 'Actores', 'instituciones', 'recursos'y 'oportunidades', como categorias centrales. Además, se consideró el trabajo con categorias emergentes.

\section{territarias 31}

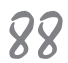

de los grupos de investigación, de sus líneas y de los mismos investigadores para que los resultados de los proyectos puedan ser socializados con las personas afectadas, las instituciones responsables y demás interesados en la temática; se busca en todo caso que los resultados sirvan para algo en esa misma realidad empírica y permita transformaciones posteriores, luego de alcanzados los objetivos propios del proyecto de investigación.

Para el estudio de los fenómenos políticos, es fundamental entonces la consideración de dos aspectos: el primero de ellos es una buena descripción que a la vez posibilite su explicación (Chuliá \& Agulló, 2012). El segundo es el que posibilita emplear metodologías precisas para un abordaje adecuado de los casos estudiados. Estos dos elementos tienen un punto de encuentro y son los conceptos (referentes teóricos) que se conviertan en la investigación en variables (se operacionalizan), esto con el ánimo de hacer estudios de casos y, tal vez más adelante, estudios comparados en ciencia política. Para esto es fundamental considerar entonces esos dos elementos: conceptos y variables.

Con estos conceptos, se desarrolló el trabajo investigativo en general, con todas sus categorías ${ }^{3}$ y variables. Así, para todos los casos, se estudió y rastreó información de la misma manera, con el mismo recorrido metodológico. Si bien era una ruta metodológica sencilla, se logró un profundo trabajo analítico, compuesto básicamente de seis momentos, que se desarrollaron $\mathrm{du}^{-}$ rante quince meses entre febrero de 2013 y mayo de 2014:

i) En los primeros dos meses de la investigación, se trabajó en la construcción del sistema categorial que expresa la postura teórico-metodológica propia del proyecto, a la vez que permitió recolectar la información. Con el sistema categorial, se facilitó la elaboración de los instrumentos de recolección de información. Para estas dos actividades, se tenían insumos adelantados en el trabajo que ha hecho la línea de investigación MFRP.

ii) $\mathrm{Al}$ mismo tiempo, en los primeros dos meses, se hizo un rastreo de información que fue complementado posteriormente con otro rastreo transcurridos ochos meses de la investigación, para contar con un completo estado del arte.

iii) Durante todo el tiempo de la investigación, se generó y recogió información: artículos y libros sobre el tema en cuestión; se participó en eventos y reuniones relacionadas con el tema de las políticas públicas territoriales de Medellín; se trataron de abordar los textos completos y las personas clave que pudieran dar cuenta de los elementos centrales de la investigación.

iv) Desde el cuarto hasta el décimo mes de la investigación, se sistematizó información, manteniendo una evaluación permanente del proceso para hacer las 
correcciones necesarias. Al final de la investigación, se mantuvo la recolección y sistematización de la información considerando la posibilidad de ejercicios investigativos posteriores.

v) Si bien en los dos últimos meses de la investigación se procedió al análisis de información, se hicieron balances durante el proyecto sobre el avance que se tenía en la información recolectada, llevando a cabo análisis parciales.

vi) Elaboración de productos de investigación. Si bien este artículo es el último producto del proyecto, durante la ejecución se realizaron otros artículos, ponencias y socializaciones que permitieron abrir discusiones en torno al tema, lo que facilitó el trabajo y lo cualificó.

Con esa ruta metodológica expuesta, se desarrolló el proyecto de manera organizada, se tiene información clasificada para poder avanzar en otros ejercicios académicos e investigativos, lo que ha facilitado la elaboración de este texto, que, aunque presenta discusiones solo sobre una parte de toda la investigación, logra expresar elementos centrales de esta y se puede leer tanto la lógica como el orden seguido.

Este artículo se desarrolla de la siguiente manera: una exposición sobre el tema de la victimización en Medellín como un problema de política pública; luego, se avanza a una definición básica de acción colectiva y se presentan algunos ejemplos de cómo ha sido en el caso de las víctimas en Medellín; después, se procede a unas definiciones de las políticas públicas territoriales y el caso concreto de la política pública de víctimas; posteriormente, se trabaja sobre una relación de la acción colectiva con las políticas públicas de víctimas en Medellín; y se finaliza con unas conclusiones generales.

\section{Antecedes institucionales de la atención a víctimas en Medellín}

El tema de la victimización y de la atención a víctimas en Medellín no es nada nuevo, mucho menos en Colombia, ni en la academia, como tampoco es un problema social que ocupe recientemente a las organizaciones sociales y no gubernamentales. Si se considera que apenas en el año 2011 se aprobó formalmente una política pública de víctimas en el país mediante la Ley 1448, se podría pensar que como problema a nivel institucional es reciente. Sin embargo, no lo es como problema público, ya que en la agenda sistémica (Aguilar, 1993) estaba expuesto y en discusión hace mucho tiempo.

En el año 1997, se aprobó en Colombia la Ley 387, que definía unos lineamientos iniciales para la atención de una parte considerable del total de las víctimas, las del desplazamiento forzado, ${ }^{4}$ y la política pública que se desarrolló después de eso sirvió de antecedente institucional para la política pública de víctimas del conflicto armado que se tiene hoy en Colombia.

El desplazamiento forzado de personas en Colombia (desplazamiento interno) fue explicado comúnmente como un efecto de
${ }^{4}$ La victimización como problema de politica pública se limitaba únicamente al desplazamiento forzado; posteriormente, se incluyen otros tipos de victimización con acciones especificas; $y$, para 2011, con la ya referenciada Ley de Victimas.

tersitarios 31 
la guerra o del conflicto armado que vive el país y que es considerado el más largo en América Latina. Así mismo, se fue abriendo paso, a finales de la década de 1990, la explicación del desplazamiento forzado no solo como consecuencia de la guerra, también como estrategia de esta (González, 1999); en la mayoría de las veces, para la apropiación de los territorios estratégicos para la guerra o para las economías legales e ilegales; en otras ocasiones, el desplazamiento busca desactivar y desarticular procesos organizativos.

La migración forzada de personas llevó a un aceleramiento de la urbanización, especialmente al crecimiento constante y desordenado de las ciudades capitales, entre ellas Medellín, segunda ciudad de Colombia después de Bogotá, y capital del departamento de Antioquia, lo que produjo "en las ciudades la sensación de una nueva explosión social, económica y política: la reconfiguración de las territorialidades, de las sociabilidades y de las identidades urbanas" (Naranjo, 2004, p. 146).

Para entender el desplazamiento forzado por la violencia en Colombia, y el asentamiento de hecho en Medellín, se debe hacer un análisis completo en el que se consideren los territorios, el conflicto armado asociado al desplazamiento, las poblaciones afectadas y las políticas públicas (Naranjo, 2007). En este artículo, la atención se centra en parte de esas categorías, aunque los demás elementos son tenidos en cuenta, se mencionan de manera parcial.

El debate sobre el número exacto de territarias 31 90 en Colombia. Un ejemplo claro lo constituye el debate sobre las víctimas del desplazamiento forzado, pues no queda duda de que se trata de una crisis humanitaria que afecta a cerca de 5.700 .000 personas, que representan por lo menos el $12 \% \mathrm{del}$ total de la población, lo que hace que, para 2014, sea el segundo país con más desplazados internos del mundo (IDMC, 2014). Para el caso de Medellín, se asientan más de 250.000 personas y, según un informe de la Personería Municipal, Medellín se ha constituido como un territorio expulsor de población, donde solo en 2012 se declararon 9.941 personas como expulsadas de algún lugar del municipio (Personería de Medellín, 2013, p. 87).

Esta dimensión cualitativa y cuantitativa del problema del desplazamiento forzado en Medellín y Colombia llevó a que en el año 1997 se emitiera la primera ley, desde la cual se comenzaba a formalizar una política pública de atención a las víctimas. En el año 2007, se diseña y se formula la primera política pública local del país para atender a las víctimas del desplazamiento forzado en Medellín, que fue resultado de las acciones tanto nacionales como departamentales y locales, a las que se sumaron instituciones y actores diversos a fin de sacar adelante una política pública territorial en la que se unían esfuerzos y recursos para la atención integral a la población desplazada (Naranjo, Lopera \& Granada, 2009).

En el año 2011, desde el gobierno nacional, se promueve y, posteriormente, se aprueba en el Congreso de la República lo que se conoce actualmente como 'Ley 
de Víctimas', y que pretende ampliar la política pública que anteriormente atendía solo a la población desplazada, ${ }^{5}$ para que incluya personas víctimas de otras acciones (desaparición forzada, secuestro, asesinato, violación, entre otros). Esto hizo que la institucionalidad existente, las rutas de acceso, el restablecimiento y la reparación de derechos a las víctimas fueran modificados, precisados y, en algunos casos, ampliados, lo que ha producido cambios significativos en la atención a las víctimas en todos los territorios: nación, departamentos y municipios.

En Medellín, que se habían establecido unas rutas y protocolos más o menos claros, se han tenido que precisar de nuevo, ampliándose a las demás víctimas, y ello ha implicado una reconfiguración de la institucionalidad, la aparición de nuevas alianzas, nuevos actores y nuevas formas en las relaciones. Igualmente, los recursos y las oportunidades han tenido modificaciones, lo que lleva a que la política pública tenga cambios significativos en Medellín y, en general, en cada territorio específico.

\section{La acción colectiva de las víctimas en Medellín}

El concepto 'acción colectiva' es amplio y puede hacer referencia tanto al actuar de los partidos políticos, de los grupos de interés, de los movimientos sociales o, incluso, a otras actividades menos estructuradas y organizadas. Para este artículo, se hace referencia a las asociadas o cercanas a la movilización social, a las acciones colectivas adelantadas o a las que se suma la población víctima del conflicto armado que habita Medellín.

Interesan las acciones colectivas que plantean desafíos "a través de una acción directa disruptiva contra las élites, las autoridades u otros grupos o códigos culturales". Cuando se habla de acciones directas o disruptivas, no se refiere necesariamente a la violencia o a la amenaza de estas. "Los desafíos colectivos suelen caracterizarse por la interrupción, la obstrucción o la introducción de incertidumbre en las actividades de otros" (Tarrow, 2012, p. 37).

Lo anterior es importante porque la mayoría de las acciones colectivas de las víctimas no hacen uso de la fuerza física, pero la presencia permanente en espacios institucionales, y muchas de sus reivindicaciones, intervenciones, demandas, insistencias y denuncias plantean desafíos a las instituciones responsables de atender su situación, lo que mantiene la incertidumbre incluso en las políticas públicas. Ya no es solo la incertidumbre para las víctimas por el conflicto armado, se trata también de crear incertidumbres en las instituciones y sus funcionarios, en la medida en que se mantienen los desafíos y las demandas.

\subsection{Definiciones básicas de la acción colectiva de víctimas}

Es necesario anotar que la acción colectiva de las víctimas del conflicto armado y la concreción de experiencias organizativas donde se han construido lazos identitarios superan su condición de víctimas, puesto
5 Si bien existía normatividad y acciones orientadas a atender situaciones asociadas a otras formas de victimización, en ningún otro caso había una politica pública como la que se tenía para atender a las victimas del desplazamiento forzado por la violencia. tersitarios 31

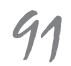


${ }^{6}$ Véase, por ejemplo: Conferencia Episcopal de Colombia et al. (2001); González Gil (2010); González Díaz et al. (2009); González Diazetal. (2012).

\section{tersitarias 31}

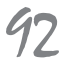

que, más allá de eso, comparten "aprendizajes previos y rasgos comunes de su pertenencia a un tipo de comunidad determinada, pero también en tanto la experiencia compartida de la violencia ha generado un nuevo espacio de configuración de nuevas sociabilidades y de nuevos rasgos identitarios" (González, 2010, p. 32), y que se ha fortalecido luego de la promulgación de la Ley de Víctimas y, en el caso de Medellín, con las acciones conjuntas que se han venido adelantado por lo menos desde el año 2011, en el que hay reivindicaciones comunes.

Se encuentra que las acciones colectivas de las víctimas han sido diversas y complejas, como lo fueron cuando eran exclusivamente de población desplazada, donde

no es posible establecer fronteras precisas entre la acción y la inacción: los actores sociales ensayan formas, no siempre circunscritas a los aprendizajes previos o a los repertorios históricos, sino que despliegan una capacidad creativa ilimitada en la búsqueda de su propio camino contestatario. Una combinación de mecanismos que oscilan entre la legalidad y la ilegalidad, entre la autonomía y la enajenación, entre la subordinación y la emancipación, entre resistir, acomodarse o movilizarse (González, 2010, p. 73).

Para el caso concreto de las acciones colectivas, se puede acudir entonces a los desarrollos del Instituto de Estudios Políti$\cos ^{6}$ en el tema, no obstante, por cuestiones de espacio, se retoma en este artículo la definición de acción colectiva elaborada por
Jonathan Murcia (2011), que, aunque se refería a la acción colectiva de la población desplazada, es pertinente para este trabajo. Se entiende entonces como

una acción conjunta intencionada de individuos autorreconocidos como actores sociales y que cuentan con sus propios principios reivindicativos. Puede ser breve o mantenida, monótona o dramática, institucionalizada, disruptiva o violenta. Responde a una construcción subjetiva de los individuos que participan en ella, quienes forjan una identidad común a partir de su condición social, su exclusión, su vulneración, sus intereses y sus reivindicaciones materiales y/o simbólicas. Esta acción colectiva implica relaciones, tanto de colaboración como de confrontación con respecto al Estado; es decir, movilizándose en el marco de las instituciones o a través de métodos contenciosos (Murcia, 2011, p. 28).

Se entienden las acciones colectivas de las víctimas de una manera amplia, pero se delimitan a las que son adelantadas por ellas mismas, o en las que por lo menos se mantiene la iniciativa y la autonomía de las organizaciones y colectivos de víctimas; en todo caso, son acciones que se orientan a acceder a recursos y a suplir sus necesidades en algunos casos de manera autónoma y autogestionada, con el acompañamiento de organizaciones comunitarias y no gubernamentales, tomando distancia del Estado; y, en otros casos, con el acompañamiento o con la demanda a las instituciones estatales. A continuación, se presenta una corta 
periodización de las acciones colectivas de las víctimas.

\subsection{Las acciones colectivas de las víctimas del conflicto armado en Medellín}

En la línea de investigación MFRP, se ha construido una periodización para la acción colectiva de la población desplazada en Medellín que se ha relacionado a su vez con las políticas públicas de atención a la población. Para este texto, se retoma esa periodización en la que se han identificado dos momentos o ciclos: el primero, 19952003 y el segundo, 2004-2010 (González \& Granada, 2012). A esta periodización, se agrega un tercer momento, entre los años 2011-2014. Se describen brevemente.

El primer momento va hasta el año 2003 , se tienen las acciones de la población víctima que llega a Medellín, son especialmente acciones directas expresadas en la ocupación de predios y en "la toma de instituciones públicas ante los eventos de desalojo, además de la interposición de recursos legales" (González \& Granada, 2012, p. 110); es un período en donde se crean las primeras organizaciones de población desplazada, así como la aparición o fortalecimiento de otras organizaciones de víctimas: Asociación Nacional de Ayuda Solidaria (Andas); Movimiento Social de Desplazados (Mosda); coordinación de organizaciones no gubernamentales; Asociación de Familiares de Detenidos - Desaparecidos- (Asfaddes), que surge desde 1983; Madres de La Candelaria, que surge en 1999; así como muchas otras organizaciones de víctimas nacionales y locales. Algunas de ellas conformarían en el año 2005 el Movimiento Nacional de Víctimas de Crímenes de Estado (Movice).

Ese período finaliza con la disminución de la intensidad de las acciones "tras la agudización del conflicto armado en la ciudad, la estigmatización generalizada de la población desplazada y las acciones de violencia que afectan directamente la población" (González y Granada, 2012, p. 111). Es un período en el que no hay políticas públicas claras de atención a la población desplazada en lo local, salvo algunos lineamientos que comenzaron desde el año 1997 con la Ley 387, lo demás eran acciones represivas de desalojos forzados y de negación de la atención.

El segundo momento va desde el año 2004 hasta 2010 , en este

se fortalecen las acciones de la población desplazada en lugares y escenarios institucionales, por vías formales, logrando ser reconocidos como actores sociales y políticos, y empieza a transformarse la forma de participar o tomar parte en lo público. La participación de la población en escenarios de política pública confiere una particularidad a este período, sin embargo, las acciones de hecho continúan porque son valoradas como un medio útil para presionar respuestas urgentes de las administraciones (p. 111).

Es un período que está precedido por pronunciamientos de la Corte Constitucional a favor de la población desplazada y un territarias 31

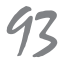


interés significativo del gobierno nacional por las víctimas del secuestro; en los demás casos, las víctimas cuentan con pocos aliados en los escenarios y lugares institucionales, pero se van fortaleciendo muchas de estas organizaciones a pesar de la persecución y represión de la que son objeto, como es el caso del Movice.

En Medellín, se presenta en ese período un fortalecimiento político, administrativo y presupuestal de la atención a la población desplazada, se consolidan espacios para su participación formal, y esto crea bases importantes para la política pública de víctimas en lo local luego del año 2011.

Con la aprobación de la Ley de Víctimas y Restitución de Tierras en el año 2011 , se hace un reconocimiento formal, jurídico y político de la condición de las víctimas en Colombia; esto a su vez ocasiona cambios en las políticas territoriales que ya existían para entonces y en las mismas acciones de las organizaciones de víctimas, marcando el tercer momento entre 2011 y primeros meses de 2014.

Históricamente, las víctimas han priorizado, especialmente de manera individual, las acciones orientadas a crear las condiciones mínimas para preservar la vida ante una situación precaria que se agudiza con la victimización. Sin embargo, las víctimas organizadas en Medellín han ido priorizando y realizando acciones orientadas a cualificarse políticamente y para fortalecer las acciones colectivas, como ha sido la elección y primeros meses de funcionamiento de la Mesa de Participación de Víctimas del municipio de Medellín, que fue elegida en propiedad en el año 2013 y que es acompañada por la Subsecretaría de Víctimas y por la Personería de Medellín.

Como se anotó para el período anterior, 2004-2010, el hecho de que las víctimas hagan acercamientos y participen en espacios institucionales no hace que renuncien a su autonomía, mantienen la acción colectiva incluso con acercamientos 'selectivos', se aproximan a unas instituciones y trabajo mancomunadamente, con otras hay oposiciones casi que permanentes y profundas.

En octubre de 2013, la Mesa de Participación de Víctimas de Medellín define un plan de trabajo, que, aunque con problemas y obstáculos, es ejecutado y va marcando formas de actuar y de relacionarse con las instituciones y otros actores de la política pública. En ese plan, las organizaciones priorizaron: i) la planeación de sus propias acciones, ii) la organización, participación e incidencia política, y iii) el control social, haciendo explícitas sus orientaciones por el fortalecimiento organizativo, social y político (Mesa de Participación de Víctimas de Medellín, 2013).

Esta periodización muestra cómo ha ido evolucionando la organización y accionar colectivo de las víctimas en Medellín: en el último período señalado, en el que se resalta la labor organizativa y política, igualmente, se presentan otras acciones que vienen de los períodos anteriores, se mantienen las formas organizativas en los territorios: las acciones de hecho como la apropiación de predios para acceder a un techo aunque sea provisional, la organiza- 
ción en los asentamientos para la mejora de estos y, obviamente, de manera individual, familiar y colectiva, las acciones por la subsistencia y la preservación de la vida.

Aunque muchas de las víctimas continúan con necesidades básicas insatisfechas, han sido capaces de vincular a esas demandas acciones organizativas de largo aliento y no solo de subsistencia, movilizaciones sociales, demandas por la verdad, la justicia y la reparación, la organización política con participación en espacios estatales y sociales en los que trabajan por acceder, satisfacer y gozar de los derechos en todas sus dimensiones. Con estas características, las víctimas organizadas llegan a escenarios de políticas públicas territoriales, como se verá en el apartado siguiente, se relacionan con otros actores, disponen de recursos, aprovechan oportunidades y actúan en los escenarios institucionales.

\section{Políticas públicas territoriales}

\subsection{Definiciones sobre las políticas públicas territoriales}

Es importante precisar que en este apartado se resalta el componente propiamente político de las políticas públicas; de estas, se destaca el lugar protagónico que tienen tanto las instituciones estatales como los diversos actores sociales en los diferentes momentos y escenarios de las políticas públicas, y que los procesos de política pública son resultado de los conflictos y las negociaciones; se trata de acciones dinámicas que superan los lugares institucionales, aunque estos sigan siendo importantes (Granada, 2012). En las políticas, intervienen instituciones, actores y redes de estos, que, con el acceso y uso de recursos, y ante la presencia de oportunidades, hacen posible que las políticas públicas se lleven a cabo como resultado de procesos políticos en los que se trata de modificar o mantener una situación que ha sido problematizada.

Para el caso de las políticas públicas territoriales, se produce una reconfiguración de las políticas nacionales, aparecen nuevos actores que no estaban antes, se convierten en obstáculos o impulsores de aquellas. Al mismo tiempo, se abren y se cierran oportunidades, mientras los recursos se agotan, se diversifican o se multiplican. En el diseño y formulación de las políticas públicas, no está implicado solo el Estado, se produce la participación de diversos actores, que, generalmente, también han estado presentes en la formación de la agenda pública y en la inscripción de los problemas en la agenda gubernamental. Se entiende que los diferentes ámbitos territoriales complejizan las políticas públicas, "inclusive, realzando la necesidad de la coordinación no jerárquica de los actores públicos, privados, sociales y comunitarios, a través de todos los niveles de gobierno en las redes de política pública" (Naranjo, Lopera \& Granada, 2009, p. 87).

En los territorios, se configuran redes de política pública en donde los actores movilizan recursos, se instalan en marcos culturales amplios y aprovechan las oportunidades políticas, esquivando obstáculos y 
${ }^{7}$ El término political circuits es usado por Charles Tilly (2003) haciendo referencia a la acción colectiva. Aqui se retoma para el caso de la politica pública y se aprovecha el potencial explicativo del concepto en el que se cruzan variables para avanzar en interpretaciones más complejas del fenómeno.

\section{territarias 31}

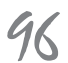

restricciones. Entre instituciones y actores, existen condiciones desiguales, dependiendo de cómo se distribuyen los recursos, cómo se interpretan los marcos culturales y cómo se entienden las oportunidades. De todas formas, de esas relaciones entre actores se tienen repertorios de acción en diversos escenarios de política, se mantienen las pugnas por los significados y las representaciones de los problemas públicos (Naranjo, Lopera \& Granada, 2009, p. 87). Esas interacciones entre actores sociales e institucionales, recursos, marcos culturales, oportunidades y restricciones, repertorios, significados y representaciones, que en cada territorio son construidas en un contexto histórico, son las que les dan forma a las políticas públicas locales, más allá de las buenas intenciones en los órdenes superiores, de los diseños y formulaciones generales que se hacen para todo un territorio nacional. En las políticas públicas locales, el Estado central no pierde protagonismo, ni queda subsumido a la lógica territorial, se entiende que en los factores explicativos siguen figurando variables importantes, como las instituciones nacionales que hacen presencia en los territorios, entes de control público, agencias de cooperación internacional y otras instituciones y actores que destinan recursos para influir en las políticas públicas territoriales (Naranjo, Lopera \& Granada, 2009).

Los territorios locales son

la instancia social, económica e institucional a la cual se puede referir el proceso de políticas públicas. El punto de partida es el reconocimiento de la lógica de proximidad del tratamiento de las necesidades locales y regionales, que otorga claras ventajas a los actores locales o regionales para su enfrentamiento, pero al tiempo, el reconocimiento de que estos problemas les son propios y que son de su competencia y responsabilidad (Naranjo, Lopera \& Granada, 2009, p. 94).

Se resalta de las políticas públicas en los territorios las capacidades propias de estos, de las instituciones y actores que se encuentran allí, sus activos, sus dinámicas, el conocimiento que tienen de sus entornos, las ventajas territoriales, sus visiones y proyectos. Así como la posibilidad de articular políticas, instituciones y territorios con las metas y objetivos que tienen para sus localidades.

El criterio territorial puede facilitar la implementación de las políticas públicas, al tiempo que posibilita asumir la responsabilidad de las metas y de los actores; se valoran las potencialidades, hace más viable la negociación donde los actores están más cerca, se hace un mejor trámite del conflicto; la información y la participación están más cercanas de actores débiles o con menos recursos; el territorio es entonces un escenario de articulación y es el lugar estructurante de la política pública (Echeverri, 2008).

Es entonces en los territorios en donde se hace palpable, más fácil de observar, el proceso de la política pública, o mejor, el circuito político ${ }^{7}$ que se expresa en el proceso de la política pública y que implica i) actores: internacionales, nacionales, depar- 
tamentales, municipales; ii) recursos: materiales, cognitivos, simbólicos, discursivos; iii) escenarios públicos, privados, estatales, institucionales, sociales; iv) oportunidades, amenazas y restricciones para la acción, así como v) los diferentes ciclos de la política pública manifiestos en un mismo momento: agendas públicas y gubernamentales abiertas, rediseño de acciones, implementación y evaluación de la política, al igual que otras variables que hacen parte de los circuitos políticos.

\subsection{De las políticas nacionales en los territorios}

La implementación de las políticas públicas en los territorios debe ser entendida como un momento social y político, no solo una expresión administrativa. Así es en el caso de interés para este texto, en donde las políticas públicas que llegan al territorio han abierto las agendas públicas y gubernamentales locales en torno al problema público que pretende atender, al igual que se abre la discusión sobre la política pública misma como parte del problema público. En algunos casos, como el de las víctimas, no solo se abren las agendas locales, también se redefinen acciones y se abren procesos de rediseño, lo que cuestiona la idea de una sola forma de implementar la política nacional; en los territorios, se produce una suerte de 'hibridación' de las políticas públicas, en donde se ensayan, muchas veces con éxito, ajustes al diseño y otras formas de implementarlas.
Como lo señala Jolly,

la gobernabilidad en Colombia sólo es posible mediante políticas públicas híbridas, hijas del 'matrimonio indisoluble de la sectorialidad y de la territorialidad', de la 'secterritorialidad', que combina en proporción variable lógica sectorial (o sectorialidad, que implica centralización) y lógica territorial (o territorialidad, que implica descentralización), gracias a un modo de gobierno híbrido, la 'gobiernancia' del territorio, ésta es una 'dosificación' compleja entre gobier-no y gober-nancia (2010, p. 34).

Las experiencias más exitosas son aquellas que se han basado en enfoques de derechos, en los que los ajustes locales tienen como propósito y principio la garantía de derechos orientando las acciones a restablecer y reparar los que han sido afectados. En ese enfoque de derechos, se expresan lo que han sido los enfoques diferenciales tanto poblacionales como territoriales, que resaltan, reconocen y promueven la atención según las necesidades igualmente diferentes de las poblaciones afectadas y de sus territorios.

Se retoma la hipótesis trabajada por Naranjo, Lopera y Granada, desde la que se afirma que las políticas públicas diseñadas desde la centralidad "no consideran, ni adecuada ni suficientemente, las condiciones y características de entidades territoriales de un nivel distinto al nacional" (Naranjo, Lopera \& Granada, 2009, p. 84), lo que se manifiesta luego de manera negativa tanto en la implementación como en la evaluación territarias 31 
de las políticas públicas en los territorios descentralizados: "Estos diseños podrían ser descentralizados y corresponsables, entre la nación y las entidades territoriales, lo que le daría eficacia decisional y legitimidad democrática a esta política pública" (Naranjo, Lopera \& Granada, 2009, p. 84).

Se cuestiona el control que en muchas ocasiones se pretende hacer de la implementación en los territorios, tratando que las políticas operen como han sido ideadas en la centralidad, con lo cual se cuestiona igualmente la idea de que algunas políticas públicas, a pesar de estar bien formuladas y ser garantistas en las consideraciones que hacen, fallan en el momento de la implementación; muchas de las acciones estatales no consideran las variaciones de y en los territorios.

Sin duda, esta discusión recae sobre los procesos, acciones y momentos de la implementación de las políticas territoriales, pero implica discutir los diseños y las formulaciones que se han hecho de estas, así como la reconstrucción de las agendas pública y gubernamental, ir sobre las políticas públicas que tratan de operar según las particularidades territoriales y poblacionales. Se trata de volver sobre los conflictos que se producen en lo local con las políticas nacionales, y cómo estos modifican esas mismas políticas.

Lo anterior da pie para complejizar el análisis de los momentos o ciclos en las políticas públicas territoriales: agendas, diseños, implementación y evaluación, ya que en muchos casos estos momentos, que de por sí no son cronológicos, toman una dinámica y unos tiempos diferentes en los territorios municipales. Es el caso que sirve de ejemplo en este escrito, en donde existen políticas nacionales y subnacionales sobre desplazamiento forzado implementadas en Medellín en el año 2011 al tiempo que se aprobaba una política para la atención a víctimas; de esta última, se desprenden acciones y órdenes para los territorios, que, en el caso de Medellín, y seguramente de otros tantos, se abren agendas públicas y gubernamentales locales, lo cual a la vez lleva discusiones a la nación y obliga a hacer ajustes permanentes en todos los territorios. Es una política pública que, por lo menos entre 2011 y 2013 , se reagenda, se reformula y se implementa al mismo tiempo tanto en la nación como en los territorios, se aceleran los intercambios y las relaciones en el circuito político de la política pública local.

En estos territorios, no solo se expresan de forma diferente las acciones de política pública, además lo hacen cada uno de sus momentos, y el hecho de no atender estas particularidades puede dar al traste con las buenas intenciones y los buenos diseños técnicos. Estos cambios en la política nacional han hecho que 'aparezcan' nuevos actores, especialmente organizaciones sociales y organizaciones de víctimas; con estos actores, aparecen nuevos recursos de diferente tipo y las oportunidades políticas se reconfiguran, lo que obedece en parte a que en territorios con liderazgos tan marcados como Medellín se reformulen acciones, no solo para el territorio, sino para el resto del país. 


\subsection{Los territorios en las políticas públicas}

Las políticas públicas contemplan los territorios o la territorialización por lo menos de dos formas: la primera es la delimitación que se hace del espacio de acción de la política, ya sea focalizando o priorizando poblaciones y espacios. La segunda forma, y tal vez menos común, es la de entender que los territorios tienen sus particularidades, capacidades, potencialidades, instituciones, actores, recursos y oportunidades. "La 'territorialización' de las políticas públicas se convierte en un tipo de evidencia en la acción pública, sin que se sepa aún si se trata de desconcentración, descentralización o gerencia organizacional" (Faure, 2009 , p. 418). De todas formas, esto implica una pregunta por los territorios, que debe ser complejizada más allá de procesos administrativos, rescatando especialmente el carácter político de las políticas en los territorios.

Las políticas públicas que se desarrollan de manera concreta en departamentos y municipios toman relevancia luego de los procesos descentralizadores que se han producido, sin embargo, la descentralización es solo una variable en las políticas públicas territoriales ligada fuertemente al aspecto administrativo, pero que debe ser profundizada en la medida que se vincula con otras variables de tipo político, social y económico.

Retomando a Faure, a comienzos de la década de 1990, los teóricos abordan tres vertientes complementarias que él rescata así: "Jean-Claude Thoenig (Thoenig \& Ashford, 1980) evoca la figura del Estado territorial para calificar las nuevas formas de institucionalización de la acción colectiva, el territorio (entendido como la comuna o el departamento) se convierte en el lugar principal para la definición de los problemas". La segunda vertiente la retoma de Patrice Duran (1999) con los principios de territorialidad "que guía desde entonces la acción pública conjunta con espacios de gestión políticamente estables para las comunas" (Faure, 2009, p. 420), pero en los que también se producen las 'turbulencias' de los grupos de presión, la acción colectiva no institucionalizada. La tercer vertiente de Pierre Lascoumes (Lascoumes \& Le Bourhis, 1998) "traduce estas evidencias cuando estudia los cambios de mentalidad en el seno de las administraciones públicas, y muestra que los nuevos acuerdos procedimentales desembocan en la formulación de un bien común que no es otra cosa que una construcción territorial limitada en el tiempo que no hace referencia a objetivos concebidos a nivel nacional o sectorial" (Faure, 2009, p. 421).

Habría que anotar que esa "no referencia a los objetivos concebidos a nivel nacional" se refiere no a la formulación de objetivos contrarios a aquellos, sino más bien a la construcción que hacen los territorios de sus propios objetivos con base en lo que se define desde lo nacional y con las definiciones propias de los problemas en lo local. 


\subsubsection{La descentralización en la politica pública de atención a victimas}

En el caso de las políticas públicas sobre el desplazamiento forzado, y en parte en la de víctimas, ha ocurrido que gran parte de lo que se ha descentralizado son responsabilidades para los municipios y departamentos, pero se mantienen centralizados recursos y decisiones; esto fue especialmente así en los primeros años de implementación de la política pública a finales de la década de 1990 y aproximadamente hasta el año 2004. Si bien se siguen presentando situaciones similares donde la centralidad administrativa ordena y dicta qué hacer en los territorios, estos cada vez ganan en capacidad de plantear sus posturas al orden nacional y rediseñar acciones en sus territorios.

Especialmente a partir del año 2004, luego de que la Corte Constitucional colombiana promulgara la Sentencia T-025, que declaraba un estado de cosas inconstitucional, ordenando al gobierno nacional y a los territoriales modificar sustancialmente las políticas de atención a las víctimas del desplazamiento forzado, orientándolas a la garantía y goce efectivo de derechos, lo que posibilitó mejorar las políticas tanto en lo nacional general como en los territorios.

Con la llamada Ley de Víctimas del año 2011, se produce una nueva reconfiguración de la descentralización administrativa para la atención a las víctimas, y se redistribuyen funciones y responsabilidades institucionales. Esos procesos administrativos fueron complementados en territorios como Medellín con los actores locales, sus capacidades, experiencias y recursos, que logran ampliar la política pública de atención a víctimas, sus acciones, y avanzan en la restitución de derechos, aunque aún estén muy lejos de la reparación de los derechos violados y vulnerados.

Los procesos descentralizadores, si son entendidos como meros hechos administrativos, seguirán dejando por fuera aspectos propios y fundamentales para que las políticas funcionen en los territorios; de hecho, deben dejar márgenes de maniobra mayores en los departamentos y municipios que posibiliten precisar la construcción de los problemas públicos, ajustar los diseños de las acciones de las políticas públicas y, obviamente, darles más autonomía y recursos materiales para que las acciones atiendan los problemas reconstruidos en los territorios.

\subsubsection{Los enfoques territoriales en las politicas públicas de atención a victimas}

Las políticas públicas, o los componentes de estas, que han tenido mayor impacto sobre los problemas son aquellas que han atendido cuidadosamente a las variables territoriales, ocupándose de ellas directamente; ese fue el caso de la política pública de atención a las víctimas del desplazamiento forzado en Medellín, especialmente entre los años 2008 y 2011, en donde las autoridades locales asumieron el liderazgo de la coordinación local de la política avanzando en la garantía de derechos, aunque los fracasos de la política de seguridad que mantenía los desplazamientos forzados 
desde y hacia Medellín hacían insostenible cualquier acción de restitución de derechos e imposibilitaba la reparación integral a las víctimas.

Así mismo, la garantía para las acciones de la población víctima, abriendo espacios de interlocución, integrando propuestas de estas a las políticas públicas, además de posibilitar y fortalecer las organizaciones, facilitó el trabajo político y cualificó el accionar de las instituciones en el municipio, y redundó en unas mejores políticas territoriales.

Detrás de esas políticas públicas que logran avanzar en la garantía de derechos, hay un enfoque nombrado, así mismo, de derechos, y que se expresa en lo que se llama los enfoques diferenciales, tanto poblacionales como territoriales. Respecto al primero, se destacan especialmente las diferencias de género (y sexualidades), ciclo vital (edades), (dis)capacidades, etnias y, en algunos casos, de clase o estrato socioeconómico. Para el segundo caso, se hace referencia a las capacidades, potencialidades y limitaciones de los territorios.

En algunos casos, se habla directamente de 'enfoque territorial' (Calvo, 2005); aunque este ha sido trabajado especialmente en el tema rural y de ruralidades, se destacan aspectos como su 'multidimensionalidad'. Las políticas territoriales superan los 'sectores' y deben considerar la coordinación no solo con los órdenes territoriales superiores, sino con otras políticas presentes en el territorio, y se consideran variables políticas, sociales, culturales y económicas que garanticen el éxito de las acciones.
Si se toman profundamente los enfoques diferenciales, se incluyen en los territorios las características poblacionales diferenciadas, los géneros, edades, capacidades y etnias que debe atender la política, lo que igualmente facilita y fortalece las relaciones y redes sociales. Así mismo, se reconoce la necesidad de articular los territorios partiendo de las semejanzas y diferencias que los hacen posibles, complementando políticas y atendiendo problemas que superan los territorios particulares (Calvo, 2005). Se entiende entonces que los territorios, como las personas, se articulan con otros, y que, si bien se deben atender a particularidades, hacen parte de otras estrategias que se orientan a atender la generalidad.

Los territorios tienen particularidades enmarcadas en procesos sociales y culturales más amplios, lo que los hace particulares es la dimensión social que se apoya en los actores que allí se asientan. "El potencial de desarrollo de un territorio no sólo se establece con base en su localización o su disponibilidad de recursos naturales sino, principalmente, en la capacidad de su población para construir y movilizar sus recursos" (Calvo, 2005, p. 3). A esto habría que agregar que los territorios, con base en sus capacidades y recursos, también aprovechan y crean oportunidades para que las políticas sean posibles y exitosas.

Los pobladores de cada territorio, de acuerdo con su contexto histórico, con los problemas que allí se reconstruyen, y en función de las demandas de los actores, requieren sus propias combinación y expresión de políticas, en algunos casos, de territarias 31

101 
atención a la pobreza y, en otros, avanzando al reconocimiento, garantía y goce de derechos, según las posibilidades y oportunidades del mismo territorio en relación con otros, y en todo momento considerando los diferentes actores responsables, interesados y afectados por las políticas.

"De esa forma, el diseño de las políticas públicas parte de las condiciones propias del territorio y no de la adaptación de la política nacional a éste. Mediante este enfoque, las políticas públicas encuentran mejores condiciones para ser coherentes con su propia definición, lo cual las distingue de las políticas gubernamentales tradicionales: sin participación ciudadana no puede hablarse de políticas públicas" (Calvo, 2005, p. 6).

Para el caso de interés, han sido esos intereses locales, que logran enmarcarse en los principios garantistas de políticas más amplias, pero no necesariamente en todas las acciones diseñadas, las que en ocasiones, debido a su visión centralista, imposibilitan ver las particularidades territoriales, y, de ser implementadas como se diseñan, podrían ir contra los propios principios que las sostienen.

En el caso de las políticas públicas de víctimas en Colombia, estas han llegado a considerar diferencias en la calidad de las víctimas según el actor y la acción que les da la categoría de víctimas; así mismo, según sus condiciones diferenciales naturales, pero aún son incapaces de considerar integralmente las diferencias territoriales, y son los mismos territorios quienes las reclaman, al tiempo que los pobladores pretenden profundizar la atención diferencial poblacional.
Por esto, es importante considerar que los enfoques diferenciales son más precisos en la medida en que estén integrados en la política pública, en que se entiendan las diferencias poblacionales en territorios y las de los territorios con sus poblaciones, $\mathrm{y}$ para ello juega un papel fundamental contar con víctimas organizadas, que son las que pueden dar cuenta de las características diferenciales con más detalles, pues son expertas en su situación diferencial.

De hecho, actualmente, en diferentes territorios en Colombia, se discute alrededor de los diálogos de paz; más allá de la firma de la paz entre el Estado y actores armados, está la convicción de que la paz solo es posible si se construye en los territorios, lo cual es similar con otras políticas relacionadas con la conflictividad violenta y las víctimas. La importancia de lo territorial con sus pobladores, en este caso de víctimas organizadas, para que las políticas sean viables.

\section{Entre la acción colectiva de las víctimas y las políticas públicas territoriales: una relación}

\subsection{Las relaciones entre las acciones colectivas y las políticas públicas}

En el caso de los territorios, se pueden identificar por lo menos tres formas en las que se relacionan las acciones colectivas de la población víctima y la política pública para su atención. En primer lugar, algunas de las acciones de política pública han sido condicionadas por las mismas demandas, 
exigencias y movilizaciones de las víctimas; de hecho, la misma Ley de Víctimas es producto, en parte, de la movilización de víctimas en toda Colombia.

Las organizaciones de víctimas como actores políticos entran en el circuito político del proceso de la política pública, allí en colaboración y conflicto con otros actores logran incidir en algunas decisiones, acceder a recursos y movilizar acciones a favor de su situación; si bien difícilmente pueden ser determinantes en la mayoría de las decisiones de política pública, han logrado modificar acciones e intervenciones institucionales en Medellín. En otros casos, la población víctima se suma o recibe el apoyo de otros actores sociales y políticos, es decir, participa de otras acciones colectivas en las que no está sola o no es quien lleva la iniciativa, pero termina influyendo en las políticas públicas para su beneficio. Resumiendo, esto es lo que se puede llamar "acciones de políticas públicas que son resultado de la acción colectiva" (Granada \& Murcia, 2012, p. 128).

En segundo lugar, otra relación se encuentra en que "las políticas públicas son formas de acción colectiva" (Granada \& Murcia, 2012, p. 128); en el caso de la política pública de víctimas en Medellín, y de su antecesora, la de desplazamiento forzado, "diversos actores en red movilizan recursos, visibilizan marcos culturales y se inscriben en una estructura de oportunidad política" (Naranjo, 2004, p. 87). Ha sido claro el vínculo entre actores con un interés común, una identidad por lo menos provisional, que aúnan recursos y que lograron sacar adelante la política territorial; aunque aún es pronto para evaluar la política de víctimas en el territorio, se han ido ajustando rutas y protocolos, lo que permite avanzar en la política pública.

La tercera relación es la que da cuenta de que "hay políticas públicas que producen acciones colectivas" (Granada \& Murcia, 2012, p. 128). La forma en la que se desarrolló la política local en Medellín para atender a la población afectada por el desplazamiento forzado después del año 2008 abrió oportunidades para fortalecer las organizaciones ya existentes y posibilitó la creación de nuevas organizaciones; se creó una serie de oportunidades para la acción colectiva en lo que se llamó el componente de 'reconocimiento y participación'. Con el cambio ocurrido con la política de víctimas, se producen variaciones en lo que tiene que ver con el apoyo y acompañamiento a las organizaciones de víctimas, sin embargo, permanecieron acciones, recursos y personas que mantienen oportunidades desde la política pública para la acción colectiva de las víctimas.

Como se lee, la relación entre acciones colectivas y políticas públicas es bastante amplia y se puede expresar de maneras diferentes. A continuación, se ejemplifican con la situación concreta en Medellín.

\subsection{La acción colectiva de las víctimas en la política pública territorial de Medellín}

Las acciones colectivas dependen en gran medida de las oportunidades políticas, que territarias 31

103 
son aquellas señales interpretadas por actores concretos con base en sus conocimientos y los marcos culturales en los que actúan, y que los animan a movilizarse, en este caso en el marco de una política pública concreta, sea para agendar problemas, para el diseño o en la implementación. Las oportunidades no son generales ni eternas, se materializan en contextos particulares, pueden ser incluso nacionales, pero se hacen 'realidad' en territorios más específicos, desde los cuales se pueden masificar (Granada, 2012).

Con el cambio a la política pública de víctimas, las oportunidades para la acción colectiva de las organizaciones de víctimas se 'han movido'; los actores han reconfigurado sus relaciones, alianzas y redes; algunos recursos se han redistribuido; unos actores han tomado más fuerza mientras otros se debilitan y desaparecen. De igual manera, las interpretaciones encontradas: de un lado que el gobierno nacional es muy parecido al anterior y que las víctimas no tienen mayores oportunidades, o, del otro, que el impulso y la aprobación de la Ley de Víctimas es la prueba del distanciamiento de su antecesor, también modifican la interpretación y creación que se puede hacer de las oportunidades.

El 'rediseño' que se produce de la política pública de desplazamiento forzado a la de víctimas, en las que desde lo nacional se 'reagenda' el problema, pasando de una a varias formas de victimización, así como el 'rediseño' de acciones e instituciones de la política, genera una reconfiguración de las oportunidades. En este cambio, con la reestructuración de las políticas en lo territorial, se amplía el conflicto, con lo que las alianzas y las relaciones que estaban en equilibrio se desestabilizan, las acciones colectivas se reacomodan, junto con las organizaciones que las adelantan, se abren de nuevo las agendas, se crean oportunidades para el rediseño y la implementación en lo local, el conflicto se modifica.

Es imposible saber qué pasará, pero la implementación de la política local depende en gran medida de la configuración de las oportunidades, de la interpretación y de los recursos que utilicen los diferentes actores frente a estas. Hay una modificación significativa que se expresa en actores nacionales mucho más fuertes, con mayor ánimo de intervenir y llegar hasta los territorios más apartados de la centralidad, lo que abre nuevos conflictos; en algunos territorios, facilita la implementación, pero en otros, como Medellín, son muchos los actores nuevos que aparecen, con la respectiva desestabilización de relaciones entre estos.

La acción colectiva y las oportunidades se pueden ampliar o restringir con la alteración que sufre el circuito político de la política pública, cuando existían acuerdos locales importantes que ocupaban a las instituciones en la implementación, $\mathrm{y}$ se produce una apertura de la agenda por factores externos, como es la aparición de nuevos lineamientos institucionales, las oportunidades se desestabilizan y pueden significar aperturas interesantes para actores débiles, o, por el contrario, la exclusión casi definitiva de algunos de ellos. 
Para las organizaciones de víctimas, algunos escenarios que eran legitimados anteriormente pueden desaparecer en la reglamentación nueva; si estos espacios son desautorizados en lo local, se abre el conflicto más allá de los escenarios institucionales y se redefine la agenda pública. En el caso contrario, que esos escenarios sean autorizados en lo local, lo que se puede activar es la implementación de las acciones diseñadas, puesto que los acuerdos pueden fluir con mayor facilidad, los actores ya no estarían excluidos de esos escenarios y podrían acompañar y legitimar la política diseñada. La Mesa de Participación de Víctimas de Medellín se enfrenta al reacomodo de las instituciones estatales, de las rutas de atención y de los protocolos; esta incertidumbre y las decisiones que se tomen significarán cambios para la misma acción colectiva y la relación con los otros actores de la política pública.

Se deben considerar las razones y las decisiones que toman los actores de la política para la participación y la acción colectiva en los escenarios de política pública territorial y nacional (o por fuera de estos), luego de evaluar los obstáculos y oportunidades (costos y beneficios) que se han ido instalando para acceder a esos espacios. La información siempre es incompleta (racionalidad limitada), pero puede ser suficiente para tomar decisiones que acerquen, mantengan o alejen a los actores no institucionales de los escenarios formales de la política local, y para que hagan un mayor esfuerzo y destinación de recursos en escenarios informales si hay más posibilidades allí.

\section{Conclusiones}

En este artículo, se continúa con las discusiones sobre las políticas públicas territoriales, más allá de las políticas públicas descentralizadas, o de la misma idea de políticas públicas territorializadas. Se trata de avanzar en discusiones que se ocupen de elementos propios de los territorios, una mirada 'horizontal' que permita ver especialmente los elementos políticos, en los que necesariamente influyen las políticas nacionales y sectoriales, pero en los que en ocasiones son más importantes la construcción propia del problema en lo local, los (re)diseños territoriales y el cómo se entienden los lineamientos nacionales.

Cuando se hace alusión a los actores en las políticas públicas, se está haciendo referencia a todas aquellas instituciones, organizaciones y personas que tienen responsabilidades, intereses o que son afectadas por las políticas públicas en los territorios, de ellas dependen en gran medida los éxitos y los fracasos de las políticas. En este texto, se ha resaltado la importancia de los actores sociales colectivos que hacen presencia en la política de víctimas en Medellín, pues son estos los que resignifican el problema, ampliando las acciones y la población atendida por la institucionalidad, lo que finalmente ha significado el avance en la atención en derechos.

Han tenido una especial atención las organizaciones de víctimas como formas de acción colectiva, que han ganado en la apropiación de los espacios territoriales de política pública, influyendo notoriamente territarios 31

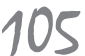


en su dinámica, desde el agendamiento constante del problema de las víctimas en Medellín, pasando por el diseño y rediseño permanente de las acciones, su ejecución y evaluación.

Por su parte, las instituciones estatales en ocasiones son un actor más, por ejemplo, en la definición del problema del desplazamiento forzado, pero tienen mayor protagonismo en la implementación de las políticas, en las responsabilidades legales que tienen en la atención, en el funcionamiento de las acciones de política, en la coordinación de estas y, finalmente, en el logro de los objetivos propuestos.

Sin embargo, hay que anotar que eso que se nombra como la 'institucionalidad' no es un todo inequívoco ni homogéneo, en ella también se presentan diferencias y conflictos, y, aunque en ocasiones la normatividad la obliga a permanecer 'alineada', son comunes las diferencias entre organismos de control, instituciones nacionales que hacen presencia en el territorio y dependencias de la alcaldía municipal, lo cual se hace más notorio en la construcción particular que se efectúa del problema de política pública y en la forma en que se entiende y se expresa.

En cuanto a los recursos, estos han sido modificados en el cambio de la política de desplazamiento forzado a la política pública de víctimas, en primer lugar, y, lo más obvio, ha sido el aumento de algunos recursos financieros, tanto desde el gobierno nacional como en el local, aunque esto no es del todo claro en territorios como Mede- llín, pero, más allá de esto, la aparición de nuevos actores en la política ha significado la ampliación de relaciones y la destinación de nuevos recursos, o de manera diferente, en los diversos momentos de la política, desde la redefinición del problema hasta la evaluación permanente que se hace de esta.

Queda entonces una línea de investigación abierta, en la que se avanzará en nuevos ejercicios de investigación en los que se indague por las relaciones entre acción colectiva y políticas públicas. Así mismo, ejercicios investigativos en los que se aborde la discusión sobre las políticas públicas territoriales y las variables que en estas confluyen: actores, instituciones, recursos, oportunidades, entre otros.

\section{Referencias}

Aguilar Villanueva, L. F. (1993). Estudio introductorio. En Problemas públicos $y$ agenda de gobierno. México: Miguel Ángel Porrúa.

Calvo Drago, J. D. (junio, 2005). El enfoque territorial en las politicas públicas. Ponencia presentada en el V Congreso Nacional de Administración Pública, Guatemala.

Chuliá, E., \& Agulló, M. V. (2012). Cómo se hace un trabajo de investigación en ciencia politica. Madrid: Los Libros de la Catarata.

Conferencia Episcopal de Colombia, Uribe de Hincapié, M. T. (Coord.), Naranjo Giraldo, G. E. , Nieto Nieto, G. P., Jaramillo Arbeláez, A. M., \& González Gil, 
A. M. (Invests.). (2001). Desplazamiento forzado en Antioquia. Bogotá: Secretariado Nacional de Pastoral Social.

Echeverri Pinilla, A. M. (2008). Red de politicas públicas. Una mirada territorial a la gestión pública. Ponencia presentada en el I Primer Congreso Nacional de Ciencia Política en Colombia, Universidad de los Andes, Bogotá.

Faure, A. (2009). Territorios/territorialización. En L. Boussaguet, S. Jacquot \& P. Ravinet (Dirs.), Diccionario de politicas públicas (pp. 418-423). Bogotá: Universidad Externado de Colombia.

González Díaz, S. M., \& Granada Vahos, J. G. (2009). Acción colectiva de las organizaciones de población desplazada en Medellín: ciclos, contextos, repertorios y perspectivas. Estudios Politicos, (35).

González Díaz, S. M., Granada Vahos, J. G. (2012). La irrupción de los desplazados en Medellín: organización, acción y respuestas institucionales. 1990-2010. En Resistencia ciudadana y acción colectiva en Colombia y América Latina: enfoques y experiencias. Medellín: Imprenta Universidad de Antioquia.

González Gil, A. (1999). Reseña de libro de la Consultoría para los Derechos Humanos y el Desplazamiento. "Un país que huye. Desplazamiento de una nación fragmentada”. Revista Estudios Políticos, (15), 151-159.

González Gil, A. (2010). Viajeros de ausencias: desplazamiento forzado y acción colectiva en Colombia. (Tesis doctoral, Universidad Complutense de Madrid, España).
Granada Vahos, J. G. (2012). Acción colectiva y oportunidades políticas en escenarios de políticas públicas. Estudios Politicos, (40), 76-97.

Granada Vahos, J. G., \& Murcia, J. A. (2012). Proyecto de investigación: Politicas públicas territoriales en Medellín, actores, recursos y oportunidades. Las politicas públicas de desplazamiento forzado, $y$ de las diversidades sexuales y de género.

Granada Vahos, J. G., \& Murcia, J. A. (2013). Informe final proyecto estado del arte sobre la relación acción colectiva y politicas públicas. Medellín.

Internal Displacement Monitoring Centre. (2013). Global statistics. Recuperado de http://www.internal-displacement. org/publications/2014/global-overview-2014-people-internally-displacedby-conflict-and-violence

Jolly, J. F. (2010). Regir el territorio y gobernar los territorios. Politicas públicas de vivienda de interés social, servicios públicos domiciliarios y educación. Bogotá, D.C.: Editorial Pontificia Universidad Javeriana.

Mesa de Participación de Víctimas de Medellín. (2013). Plan de trabajo octubre de 2013-marzo de 2014. Medellín.

Murcia, J.A. (2011). Población desplazada en Medellin: acción colectiva y reivindicación del derecho a la ciudad, 2000-2009. Medellín: Universidad de Antioquia.

Naranjo, G. (2004). Ciudadanía y desplazamiento forzado en Colombia: una relación conflictiva interpretada desde la teoría del reconocimiento. Estudios Políticos, (25), 137-160. territarias 31

107 
Naranjo, G. (2007). Desplazamiento forzado y reconfiguraciones urbanas. El caso de Medellín y el Área Metropolitana 19922002: hacia un observatorio del desplazamiento forzado de población en Medellín yel Área Metropolitana. Documento sin publicar.

Naranjo, G., Lopera, J., \& Granada, J. (2009). Las políticas públicas territoriales como redes de política pública y gobernanza local: la experiencia de diseño y formulación de las políticas públicas sobre desplazamiento forzado en el departamento de Antioquia y la ciudad de Medellín. Estudios Políticos, (35), 81-105.
Personería de Medellín. (2013). Informe sobre la situación de los derechos humanos en la ciudad de Medellín 2012. Medellín. Tarrow, S. (2012). El poder en movimiento: los movimientos sociales, la acción colectiva y la política ( $3^{\mathrm{a}} \mathrm{ed}$.). Madrid: Alianza Editorial.

Tilly, C. (October, 2003). Social movements enter the twenty-first century. Prepared for the conference on Contentious Politics and the Economic Opportunity Structure: Mediterranean Perspectives University of Crete, Rethymno. 